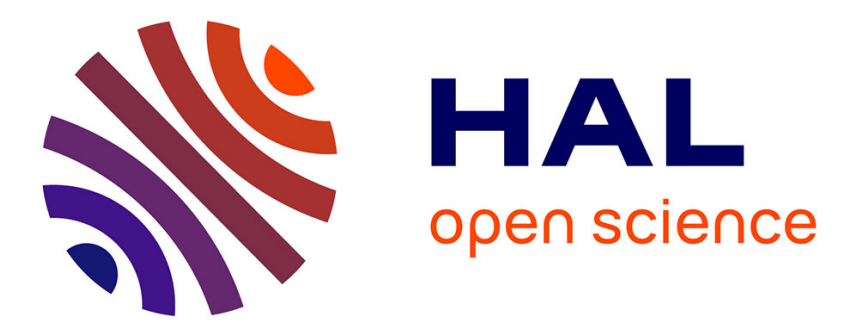

\title{
Chemical cues in the host-seeking behaviour of tracheal mites (Acarapis woodi) in honey bees (Apis mellifera mellifera)
}

John B. Mcmullan, Patrizia d'Ettorre, Mark J.F. Brown

\section{- To cite this version:}

John B. Mcmullan, Patrizia d'Ettorre, Mark J.F. Brown. Chemical cues in the host-seeking behaviour of tracheal mites (Acarapis woodi) in honey bees (Apis mellifera mellifera). Apidologie, 2010, 41 (5), 10.1051/apido/2010004 . hal-00892073

\section{HAL Id: hal-00892073 https://hal.science/hal-00892073}

Submitted on 1 Jan 2010

HAL is a multi-disciplinary open access archive for the deposit and dissemination of scientific research documents, whether they are published or not. The documents may come from teaching and research institutions in France or abroad, or from public or private research centers.
L'archive ouverte pluridisciplinaire HAL, est destinée au dépôt et à la diffusion de documents scientifiques de niveau recherche, publiés ou non, émanant des établissements d'enseignement et de recherche français ou étrangers, des laboratoires publics ou privés. 


\title{
Chemical cues in the host-seeking behaviour of tracheal mites (Acarapis woodi) in honey bees (Apis mellifera mellifera)*
}

\author{
John B. MCMUlLaN ${ }^{1}$, Patrizia d'ETTORRE ${ }^{2}$, Mark J.F. BrowN ${ }^{3}$ \\ ${ }^{1}$ School of Natural Sciences, Department of Zoology, University of Dublin Trinity College, Dublin 2, Ireland \\ ${ }^{2}$ Centre for Social Evolution, Department of Biology, University of Copenhagen, Denmark \\ ${ }^{3}$ School of Biological Sciences, Royal Holloway, University of London, Egham, TW20 0EX, UK
}

Received 18 June 2009 - Revised 23 September 2009 - Accepted 29 November 2009

\begin{abstract}
The tracheal mite, Acarapis woodi, is a widespread parasite of honey bees that can lead to colony death. A key determinant of colony mortality is the prevalence of the parasite within a colony. Prevalence depends upon transmission rates, which vary depending upon the age of potential hosts. Honey bee cuticular hydrocarbons change with age, and have been suggested to be the cue used by tracheal mites to determine whether they move to a potential host. Recently, honey bees pupated at a reduced temperature were found to have a significantly higher susceptibility to tracheal-mite infestation. In this study experiments were conducted to determine whether this susceptibility was due to a change in chemical cues. Cuticular compounds were significantly different between bees pupated at $34^{\circ} \mathrm{C}$ and $30{ }^{\circ} \mathrm{C}$, as predicted. However, behavioural tests showed conclusively that the increased susceptibility of bees pupated at the lower temperature could not be explained by these chemical differences. Other factors, such as changes in bee physiology, reduced mobility and cognitive ability, that have been shown to be caused by reduced pupation temperature, are suggested as potential mechanisms. Interestingly, these experiments provide evidence that tracheal mites only respond to gustatory and not olfactory cues. The implications of this for the behavioural strategies adopted by mites to maximise safe transmission, and a new model for mite transfer are discussed.
\end{abstract}

Apis mellifera / Acarapis woodi / tracheal mite / mite migration / pupation temperature

\section{INTRODUCTION}

The tracheal mite, Acarapis woodi, has been associated with widespread damage to honey bee colonies since the early 1900s (Bailey, 1961; Adam, 1987; Eischen et al., 1989; Otis and Scott-Dupree, 1992). The mite is an obligate parasite of the honey bee and completes its lifecycle entirely within the tracheae of the honey bee except for the transitionary period when it is moving to a new, honey bee host.

It has been known for some time that the susceptibility of bees to tracheal mites is

Corresponding author: J.B. McMullan, jmcmullan@eircom.net

* Manuscript editor: Peter Rosenkranz at its highest at time of emergence and declines rapidly with age. During normal colony conditions when brood and young bees are present, bees more than 4 days old are seldom invaded by new mites (Morgenthaler, 1931; Bailey, 1958; Lee, 1963; Giordani, 1977; Gary and Page, 1987). Susceptibility is also dependent on the strain of bee (Gary and Page, 1987) and this has been shown to be influenced to a large extent by the grooming ability of the bees (Danka and Villa, 1998, 2005; McMullan and Brown, 2006). It has also been demonstrated that reduced pupation temperature causes honey bee susceptibility to increase (McMullan and Brown, 2005). This increase in susceptibility may play a key role in the process whereby tracheal mites cause honey bee colony mortality (McMullan and 
Brown, 2009). Changes in autogrooming cannot explain this pupation temperature effect (McMullan and Brown, 2006) and hence the question remains as to what is the principal mechanism behind this increased susceptibility. What causes honey bees pupated at a lower than normal temperature to have a higher number of foundress female mites migrate to their tracheae? One possible explanation for this differential susceptibility may be the influence of chemical cues.

Hydrocarbons make up the major part of the lipid layer on the outer cuticular surface of honey bees. Branched and saturated hydrocarbons decrease rapidly from the time of emergence of new callow bees (Francis et al., 1989) and this may be used by mites to identify young bees. Phelan et al. (1991) concluded that the specific attractiveness of young callow bees to tracheal mites was determined by their cuticular compounds, and demonstrated a significant effect in three out of four honey bee test colonies. Using a similar methodology, vanEngelsdorp and Otis (2001) undertook an experiment to identify if cuticular compounds had a role in the differential resistance of different bee strains to infestation by the tracheal mite. While the results demonstrated that the mites had a preference for some bee colonies as opposed to others there was no consistency based on colony susceptibility/resistance.

Phelan et al. (1991) used hexane to extract the cuticular compounds from test bees and employed a two-choice bioassay to identify mite preference. The hexane extracts were applied to two filter papers (1 $\mathrm{cm}$ diameter), $4 \mathrm{~mm}$ apart on a plastic slide and the female mite was placed in the centre. The location of the mite after a period of 5 minutes was used to indicate a preference for one extract over the other. If mites are attracted to the cuticular extract of bees it must also be possible to elicit a response from a direct 'whole bee' approach. By presenting mites with treated bees it would be expected that a mite should express in a two-choice bioassay any preference that was present. Sammataro and Needham (1996) showed that mites placed on the thoraces of treated bees demonstrated treatmentdependent responses.
Here we ask whether chemical cues determine the increased susceptibility to tracheal mite infestation of honey bees pupated at a lower than normal temperature. To do this we used a two-pronged approach. First, we conducted behavioural choice tests on the mites. Second, we obtained profiles of the honey bee surface hydrocarbons using gas chromatography mass spectrometry. We combined the results from these experiments to enhance our understanding of the dynamics of tracheal mite transmission within honey bee colonies.

\section{MATERIALS AND METHODS}

A two-choice experiment was originally set up along the same lines as that in Phelan et al. (1991), and vanEngelsdorp and Otis (2001) with the exception that a whole bee was used in place of cuticular extract.

\subsection{Preparation of the test bees}

The source honey bees for the experiment were the control $\left(34{ }^{\circ} \mathrm{C}\right)$ and treated bees $\left(30^{\circ} \mathrm{C}\right)$ from the three colonies that were used in the pupationtemperature experiment (McMullan and Brown, 2006). The colonies were of the subspecies Apis mellifera mellifera and from beekeeper apiaries, four to eight kilometres apart, in North County Dublin, Ireland. These callow bees (less than 8 hours old), which were part of the same sample of bees used in the 2006 experiment, had been frozen and held at $-30^{\circ} \mathrm{C}$. Bees pupated at $34^{\circ} \mathrm{C}$ and $30^{\circ} \mathrm{C}$ were removed from the freezer and held at room temperature for 20 minutes to allow them to dry off. The bees to be hexane washed were put in a glass container for 10 minutes with $4 \mathrm{~mL}$ of hexane. The container was agitated at the beginning and end of the period after which the bees were removed and allowed to dry-off at room temperature.

\subsection{Initial two-choice arrangement}

A plastic slide cover had the centre line marked and a $4 \mathrm{~mm}$ diameter hole (similar in diameter to a bee thorax) was punched on each side of the centre line, the holes being $4 \mathrm{~mm}$ apart (Fig. 1a). The control and treated bees were inserted from below into the holes and wedged to the level of the 
(a)

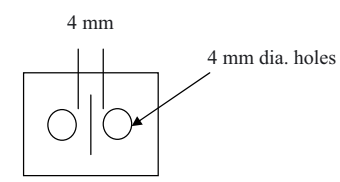

(b)

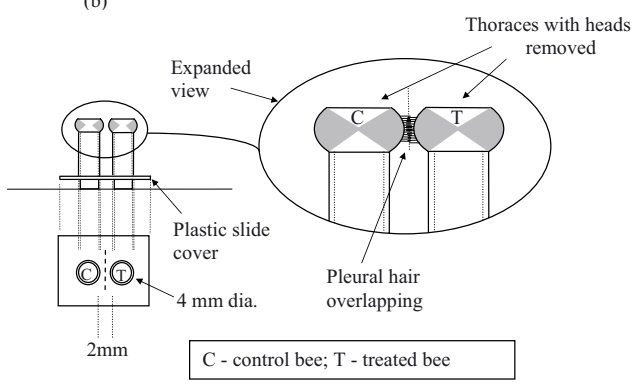

Figure 1. (a) Line drawing of the initial two-choice test arrangement similar to that used by Phelan et al. (1991) with the exception that a 'whole' bee is used in place of extract of cuticular compounds. The slide cover with $4 \mathrm{~mm}$ holes rests on a wire support with the bees inserted from below. (b) Line drawing of modified two-choice arrangement with bees mounted using coaxial straws, the inner straw passing through the $4 \mathrm{~mm}$ dia. holes in a plastic slide cover. The two bees were inserted into the inner straws, wider straws on the outside went over the wings and legs and the thoraces were pushed together to allow the plural hair to overlap. The slide cover rests on a wire support.

wing roots. The plastic slide cover with bees attached was then placed horizontally on a wire support. The bees were in a vertical axis, aligned laterally to each other and facing in opposite directions. The tests were undertaken blind. Giordani (1967) demonstrated that the highest survival rate for tracheal mites on bee pupae was at a temperature of $28{ }^{\circ} \mathrm{C}$ and relative humidity (RH) of $70 \%$. The experiment was conducted in an ambient temperature of $28( \pm 1){ }^{\circ} \mathrm{C}$ and $(\mathrm{RH})$ of $68( \pm 5) \%$. These conditions were maintained in a confined laboratory using a humidifier and meant that the removal of mites from the infested bees, their transfer and the experiment itself were undertaken in stable conditions causing the minimum environmental shock to the mites.

\subsection{Selecting female test mites}

The mites were harvested from a host colony with a mite prevalence of $>70 \%$. Flying bees in groups of about 40 were collected from the landing board of the hive using a vacuum collector. They were held, awaiting dissection, in wire cages in an incubator and fed water and 50\% (w/w) sugar syrup. The live female mites for the two-choice testing were obtained by removing the bee's head and pronotum thereby exposing the tracheae. To avoid injuring the mites, a piece of cuticle was cut around the spiracle end of the trachea and this was removed intact with the infested trachea under a stereomicroscope at 60-100X magnification and placed on a glass slide. Some salivary gland tissue was also extracted to enable the trachea to adhere to the glass slide. No more than five infested tracheae were removed simultaneously to minimise the time that the mites were outside of the dissected bee. An eyelash attached to a thin wooden probe was used to lift the mites. The female mites were lifted from a questing position on the hair attached to the cuticle at the spiracle end of the trachea or by gently opening the trachea with a dissecting needle and removing a mite. Only young (lightly bronzed) female mites and lightly pregnant mites were used. Old heavily pregnant mites tended to lack mobility and stayed fixed in one position in the test area.

\subsection{Initial two-choice test}

The experiments of Phelan et al. (1991) had significant responses in all cases where cuticular hydrocarbon extract from a bee of any age was tested against a hexane control. In order to test for a similar response, the $34{ }^{\circ} \mathrm{C}$ pupated bees as a control were tested against $34{ }^{\circ} \mathrm{C}$ pupated bees that had been washed in hexane for 10 minutes. The test was repeated for the $30{ }^{\circ} \mathrm{C}$ (unwashed vs. washed) as well as $34{ }^{\circ} \mathrm{C}$ vs. $30{ }^{\circ} \mathrm{C}$ (both unwashed). The test was carried out on one colony, colony 2 , as this colony showed the greatest change in susceptibility when pupated at $30{ }^{\circ} \mathrm{C}$ in the pupation-temperature experiment (Fig. 2). The selected female mite was placed in the centre position between the test bees and its location was scored after 5 minutes as being on the control or treated bee or on the slide cover as a no choice. A total of 16 pairs were tested for each case. Since this approach did not elicit any observable response the alternative modified approach below was employed. 


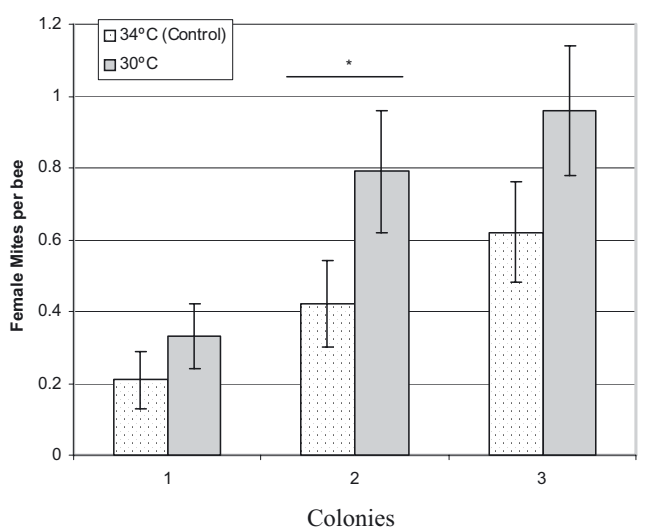

Figure 2. Mite abundance levels (mean female mites per bee) for the bees pupated at $34{ }^{\circ} \mathrm{C}$ and $30{ }^{\circ} \mathrm{C}$, from the three colonies, after a period of seven days in the inoculation cages (modified from McMullan and Brown, 2006). Statistically significant difference within colony is indicated by asterisk.

\subsection{Modified two-choice test}

An alternative two-choice approach was designed to enable the mites to be in contact simultaneously with cuticular compounds from the control and treated bees, and to make their choice using the gustatory sensors on their legs (Waladde and Rice, 1982). The head was removed from each bee to improve the visibility of the thorax, when viewed through the microscope from the top, and excess body fluid was removed with blotting paper to prevent it staining the hairs on the thorax and affecting their condition. The bees were mounted in the vertical axis within short lengths of $4 \mathrm{~mm}$ diameter straws spaced $2 \mathrm{~mm}$ apart (Fig. 1b). The thinner straws were inserted into two $4 \mathrm{~mm}$ holes that had been punched $2 \mathrm{~mm}$ apart in a plastic slide, and this held the straws in place.

The bees were pushed abdomen first into the thinner straws as far as the root of the wings, with wings and legs on the outside. They were then held in position with short lengths of wider straws that went over the inside straws and trapped the wings and legs in position. The slide cover was placed horizontally on a wire support. The bees were in a vertical axis, aligned laterally to each other and facing in opposite directions, and were tilted slightly towards each other to enable the pleural hair on the thoraces to interlock. The pleural hair was 'combed' with an eyelash probe to enhance the interlocking of the hair. Separate probes were dedicated to either the control or treated bees to avoid cross-contamination of the cuticular compounds. The hair was allowed to overlap by about a third of its length.

A selected female mite was deposited at the centre of the overlapping pleural hair. Since the female mites are large relative to the thickness of the pleural hair they were simultaneously in contact with the hair of both test bees. The mite choice was scored after 5 minutes by noting the location of the mite. A 'no' score was registered if the mite had not located itself on one or other of the two bees. The behavioural mode of the mites (questing/seeking, see below) was noted after 5 minutes and also after a period of about 3 hours. It had been hoped to dissect bees after the longer period to establish how many of the mites had migrated into the tracheae. However, after this period dissection was not possible as dark body fluid had gathered in the tracheae.

It was of some concern that the dead bees would lose their 'freshness'. To test the experimental protocol 16 pairs of samples of bees from each pupation temperature in colony 2 , were presented as an unwashed vs. washed bee choice. Eight pairs were tested within three hours of the bees being removed from freezer storage and the second batch was tested 4 to 6 hours post-removal. The mite preference for unwashed vs. washed in the first 3 hours was 13:2 respectively and the corresponding choices in the 4 to 6 hour period 8:7. This would indicate that the decomposing of the bees cloaked any difference in bee cuticular compounds in the two-choice test, as a significant difference in choices was demonstrated between the two periods $\left(\chi^{2}=3.96, P<0.05\right)$. As a result it was decided to test the bees in batches of 4 pairs and the tests were undertaken within 2 hours of the bees being removed from storage.

The permutations used to obtain the initial twochoice test for response above were repeated but this time for all three colonies as opposed to only colony 2 . For each colony 32 two-pair tests were undertaken for the $34{ }^{\circ} \mathrm{C}$ (unwashed vs. washed) and $30{ }^{\circ} \mathrm{C}$ (unwashed vs. washed). In the case of $34^{\circ} \mathrm{C}$ vs. $30^{\circ} \mathrm{C}$ (both unwashed), 48 pairs were tested for each colony.

In the migration process from old to new host bees two of the mite's critical behavioural modes, 'questing' and 'seeking', were noted. Hirschfelder and Sachs (1952) identified 'questing' as the behaviour where the mite crawls up a bee hair (seta), holds on with a leg and tries to make contact with any adjacent objects (Fig. 3). 'Seeking' on the other 


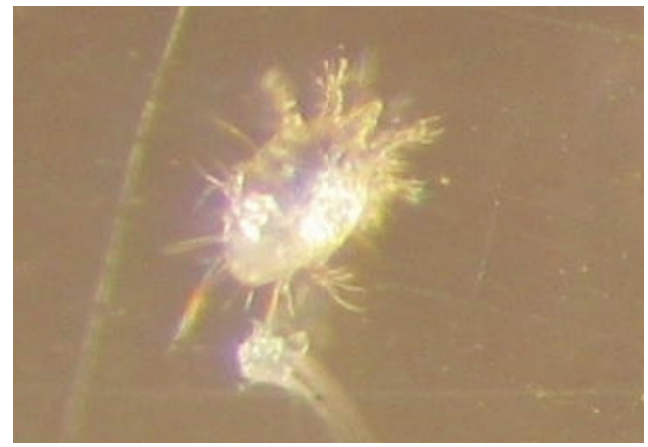

Figure 3. Photograph of mite in 'questing' mode, with its right rear leg attached to a bee hair (seta).

hand describes niche-location behaviour on the bee including finding the entrance to the spiracle.

\subsection{Chemical analyses}

Samples of frozen callow bees from each of the three colonies and $34{ }^{\circ} \mathrm{C} \& 30{ }^{\circ} \mathrm{C}$ temperature treatments per colony (six sets of samples in total) as used in the two-choice experiments, were analysed to obtain the profiles of their cuticular hydrocarbons. The chemical analysis was undertaken in the Department of Population Biology, Institute of Biology, University of Copenhagen, Denmark. Ten bees were chosen from each of the six samples. Each bee was washed in $500 \mu \mathrm{L}$ of pentane for 10 minutes. The bee was then removed from the vial and the solvent allowed to evaporate off at room temperature for approximately 30 minutes. The extract was re-diluted in $110 \mu \mathrm{L}$ of pentane before being analysed with an Agilent Technologies $6890 \mathrm{~N}$ gas chromatograph (capillary column: HP5MS 30 m X $250 \mu \mathrm{m}$ X $0.25 \mu \mathrm{m}$; injector: splitsplitless; carrying gas: helium at $1 \mathrm{~mL} / \mathrm{min}$ ), coupled with a 5975 mass selective detector $(70 \mathrm{eV}$ electron impact ionisation). The temperature programme ranged from $70{ }^{\circ} \mathrm{C}$ to $280^{\circ} \mathrm{C}$ at $10{ }^{\circ} \mathrm{C} / \mathrm{min}$. and from $280{ }^{\circ} \mathrm{C}$ to $310^{\circ} \mathrm{C}$ at $3{ }^{\circ} \mathrm{C} / \mathrm{min}$., and held at $310^{\circ} \mathrm{C}$ for $10 \mathrm{~min}$. Injections were performed by an automatic liquid sampler 7683B. Compounds were identified on the basis of their mass spectra. The presence of 29 regularly occurring hydrocarbons was identified and the area for each peak was calculated for each bee with the software Chemstation (Agilent Technologies).
Table I. Initial two-choice arrangement. Female tracheal mite choices when presented with 16 pairs of bees, made up of unwashed (uw) and hexane washed (w) bees, pupated at $34{ }^{\circ} \mathrm{C}$ and $30{ }^{\circ} \mathrm{C}$ from colony 2 . The thoraces of bee-pairs protruded through holes spaced at $4 \mathrm{~mm}$ in a cover slip and the mites were placed in the centre.

\begin{tabular}{lcc}
\hline Choice & $\begin{array}{c}\text { Outcome } \\
\text { uw:w } \\
\text { (no choice) }\end{array}$ & $\begin{array}{c}\chi^{2} \text { test }(P \text { value }) \\
\text { choice: } n \text { no choice }\end{array}$ \\
\hline $34{ }^{\circ} \mathrm{C}\left(\right.$ uw):34 ${ }^{\circ} \mathrm{C}(\mathrm{w})$ & $1: 2(13)$ & $6.25(P=0.01)$ \\
$30{ }^{\circ} \mathrm{C}($ uw $): 30{ }^{\circ} \mathrm{C}(\mathrm{w})$ & $2: 0(14)$ & $9.0(P<0.01)$ \\
$34{ }^{\circ} \mathrm{C}(\mathrm{uw}): 30{ }^{\circ} \mathrm{C}(\mathrm{uw})$ & $1: 2(13)$ & $6.25(P=0.01)$ \\
All choices & $4: 4(40)$ & $21.3(P<0.01)$ \\
\hline
\end{tabular}

\subsection{Statistical analyses}

The data from the two-choice tests established, (i) if the female mites made a choice, (ii) the preferences between unwashed and washed bees and (iii) the preferences between $34^{\circ} \mathrm{C}$ and $30^{\circ} \mathrm{C}$ treatments. All of the data were analysed using chisquare tests. The chemical profiles of the bees from the three colonies and two temperature treatments were compared using a multivariate analysis. Peak areas were transformed using a Z-transformation (Aitchison, 1986) and then analysed with a principal component analysis (PCA) to reduce the number of variables, which were subsequently analysed using discriminant analysis (DA) in STATOSTICA (StatSoft).

\section{RESULTS}

\subsection{Two-choice tests}

The initial two-choice arrangement with the test bees $4 \mathrm{~mm}$ apart did not elicit a meaningful response (Tab. I). After release, the mites generally moved in circles relatively close to the centre of the slide or moved, at what appeared to be at random, in a particular direction. On occasions when a mite moved close to one of the bees there was no evidence that the mite had any awareness of the proximity of the bee (for example, mites did not turn towards the bee). Consequently, the number of individual choices made by the mites (that is, the number of times that they walked onto a bee) 
Table II. Modified two-choice arrangement. Female tracheal mite choices when presented with 32 pairs of unwashed (uw) and hexane washed bees (w), pupated at $34{ }^{\circ} \mathrm{C}$ and $30{ }^{\circ} \mathrm{C}$ from the three colonies. The plumose hair of the bee-pairs was overlapping and the mites were placed in the centre.

\begin{tabular}{|c|c|c|c|}
\hline \multirow[t]{2}{*}{ Colony } & \multirow{2}{*}{$\begin{array}{c}\text { Choice } \\
\text { uw:w (no choice) }\end{array}$} & \multicolumn{2}{|c|}{$\chi^{2}$ test $(P$ value $)$} \\
\hline & & choice:no choice & uw:w \\
\hline \multicolumn{4}{|l|}{ Colony 1} \\
\hline $34^{\circ} \mathrm{C}$ & $12: 17(3)$ & $21.2(P<0.01)$ & $0.86(P=0.36)$ \\
\hline $30^{\circ} \mathrm{C}$ & $16: 13(3)$ & $21.2(P<0.01)$ & $0.31(P=0.58)$ \\
\hline Total (Col. 1) & $28: 30(6)$ & $42.3(P<0.01)$ & $0.07(P=0.80)$ \\
\hline \multicolumn{4}{|l|}{ Colony 2} \\
\hline $34{ }^{\circ} \mathrm{C}$ & $21: 8(3)$ & $21.3(P<0.01)$ & $5.80(P=0.02)$ \\
\hline $30{ }^{\circ} \mathrm{C}$ & $21: 9(2)$ & $24.5(P<0.01)$ & $4.80(P=0.03)$ \\
\hline Total (Col. 2) & $42: 17(5)$ & $45.6(P<0.01)$ & $10.59(P<0.01)$ \\
\hline \multicolumn{4}{|l|}{ Colony 3} \\
\hline $34^{\circ} \mathrm{C}$ & $17: 10(5)$ & $15.1(P<0.01)$ & $1.81(P=0.17)$ \\
\hline $30^{\circ} \mathrm{C}$ & $19: 9(4)$ & $22.2(P<0.01)$ & $3.57(P=0.05)$ \\
\hline Total (Col. 3) & $36: 19(9)$ & $33.1(P<0.01)$ & $5.25(P=0.02)$ \\
\hline \multicolumn{4}{|l|}{ All colonies } \\
\hline $34^{\circ} \mathrm{C}$ & $50: 35(11)$ & $57.0(P<0.01)$ & $2.65(P=0.10)$ \\
\hline $30^{\circ} \mathrm{C}$ & $56: 31(9)$ & $63.3(P<0.01)$ & $7.18(P<0.01)$ \\
\hline \multicolumn{4}{|l|}{ Col. $2 \& 3$} \\
\hline $34^{\circ} \mathrm{C}$ & $38: 18(8)$ & $36.0(P<0.01)$ & $7.14(P<0.01)$ \\
\hline $30^{\circ} \mathrm{C}$ & $40: 18(6)$ & $42.2(P<0.01)$ & $8.34(P<0.01)$ \\
\hline
\end{tabular}

was so low as to yield no worthwhile comparisons. In all only 8 choices were made out of 48 two-pair tests representing a significant no-choice preference $\left(\chi^{2}=21.3, P<0.01\right)$. The experiment demonstrated that the mites were quite mobile in this new environment and those mites that did not find one of the two bees could still be seen moving on the slide cover for up to three hours. These results suggest that mites cannot detect dead host bees from a distance, through olfaction, and thus we used the second experimental protocol to examine host-choice behaviour.

When the choices between hosts described above were presented to the mites in the modified two-choice arrangement (with the interlocking pleural hair) the choice (vs. no choice) option was significant in all cases, with most mites choosing a potential host bee (Tabs. II and III). This is in stark contrast to the initial experimental protocol. However, the choices made by mites between hosts varied depending upon host colony (Tab. II).

Mites presented with bees from colony 1 expressed no significant preference for an unwashed as opposed to a washed bee (Tab. II). In contrast, when presented with potential hosts from colonies 2 and 3 a significant preference $(P<0.05)$ was expressed for the unwashed bee in 3 out of 4 cases (Tab. II). There was also a significant preference for the unwashed bees when data for the treatments were combined for colonies 2 and $3\left(\chi^{2}=10.59\right.$, $P<0.01$ and $\chi^{2}=5.25, P=0.02$, respectively) and when colonies were combined for treatments $34{ }^{\circ} \mathrm{C}$ and $30{ }^{\circ} \mathrm{C}\left(\chi^{2}=10.59\right.$, $P<0.01$ and $\chi^{2}=5.25, P=0.02$, respectively).

The mites did not have a significant preference for $30{ }^{\circ} \mathrm{C}$ as opposed to $34{ }^{\circ} \mathrm{C}$ pupated bees (Tab. III). While the mites did choose bees pupated at $30{ }^{\circ} \mathrm{C} 26$ times compared to 
Table III. Modified two-choice arrangement. Female tracheal mite choices when presented with 48 pairs of bees pupated at $34^{\circ} \mathrm{C}$ and $30^{\circ} \mathrm{C}$, from the three colonies. The plumose hair of the bee-pairs was overlapping and the mites were placed in the centre.

\begin{tabular}{lccc}
\hline Colony & $\begin{array}{c}\text { Choice } \\
34{ }^{\circ} \mathrm{C}: 30{ }^{\circ} \mathrm{C} \\
\text { (no choice) }\end{array}$ & choice:no choice & \multicolumn{2}{c}{$\chi^{2}$ test $(P$ value $)$} \\
\cline { 3 - 4 } & $17: 26(5)$ & $30.1(P<0.01)$ & $1.88(P=0.17)$ \\
\hline Colony 1 & $19: 25(4)$ & $33.3(P<0.01)$ & $0.82(P=0.37)$ \\
Colony 2 & $36.7(P<0.01)$ & $0.20(P=0.66)$ \\
Colony 3 & $24: 21(3)$ & $100.0(P<0.01)$ & $1.09(P=0.30)$ \\
All colonies & $60: 72(12)$ & $169.0(P<0.01)$ & $0.10(P=0.75)$ \\
Col. 2 \& 3 & $43: 46(7)$ & & \\
\hline
\end{tabular}

17 times for $34{ }^{\circ} \mathrm{C}$ pupated bees for colony 1 $\left(\chi^{2}=1.88, P<0.17\right)$ the combined data for colonies 2 and 3 show a 46:43 non significant preference for $30{ }^{\circ} \mathrm{C}$ compared to $34{ }^{\circ} \mathrm{C} \mathrm{pu}$ pated bees $\left(\chi^{2}=0.10, P<0.75\right)$.

In $81 \%(271 / 336)$ of the bee-pairs undertaken in the modified two-choice arrangement, the mites were in seeking mode when scoring was undertaken at the end of 5 minutes. After three hours less than a quarter of the mites remained on the bees, these being fairly evenly divided between seeking and questing (39:43). In a few cases the mites could be seen in a feeding position on the thorax cuticle or in the thorax dorsal groove.

\subsection{Chemical analysis}

The cuticular hydrocarbons on the honey bee samples were those typical of the species, i.e. a mixture of linear, branched and doublebonded configurations with chain lengths ranging from $\mathrm{C} 19$ to $\mathrm{C} 33$. The chemical profile of bees reared at $30{ }^{\circ} \mathrm{C}$ is clearly separated from that of bees reared at $34{ }^{\circ} \mathrm{C}$ by a discriminant analysis including three colonies and thus six groups (Fig. 4 Wilks' Lambda: $\left.0.0049, F_{[45,204]}=10.377, P<0.0001\right)$.

The difference due to the rearing temperature had such an important effect on the bee cuticular hydrocarbons that it masked the effect of the origin of the colony. Indeed, a discriminant analysis based only on two groups (bees reared at $30{ }^{\circ} \mathrm{C}$ and $34{ }^{\circ} \mathrm{C}$ ), independent of the colony, is highly significant (Wilks' Lambda: $\left.0.1669, F_{[9,49]}=27.171, P<0.0001\right)$.

\section{DISCUSSION}

\subsection{Increased susceptibility due to reduced pupation temperature}

We found no evidence that cuticular compounds determine the increased susceptibility to tracheal mite infestation of honey bees pupated at $30{ }^{\circ} \mathrm{C}$ compared to $34{ }^{\circ} \mathrm{C}$ (Tab. III). Mites that migrated to a bee in the two-choice experiment did not differentiate between a bee pupated at $34{ }^{\circ} \mathrm{C}$ compared to one pupated at $30{ }^{\circ} \mathrm{C}$. While the chemical analysis (Fig. 4) indicated there was a clear distinction between the cuticular hydrocarbons in the two temperature treatments this did not appear to be used by the mites in their host choice.

It was demonstrated in earlier research that reduced autogrooming was only implicated to a limited extent in the increased susceptibility due to reduced pupation temperature (McMullan and Brown, 2006). In this paper there was no evidence that the mites use cuticular hydrocarbons to express a preference for callow bees pupated at the lower temperature (Tab. III). Hence since there is no evidence in this case that honey bee differential grooming or cuticular hydrocarbons are important factors in determining honey bee susceptibility, the relative physiology of the bees may be the factor that causes more founding female mites to migrate to bees pupated at a lower temperature. There is some evidence to support this conclusion. First, the relationship between bee susceptibility and bee age (the susceptibility curve) has a high initial susceptibility for new callow bees and this rapidly diminishes to near 


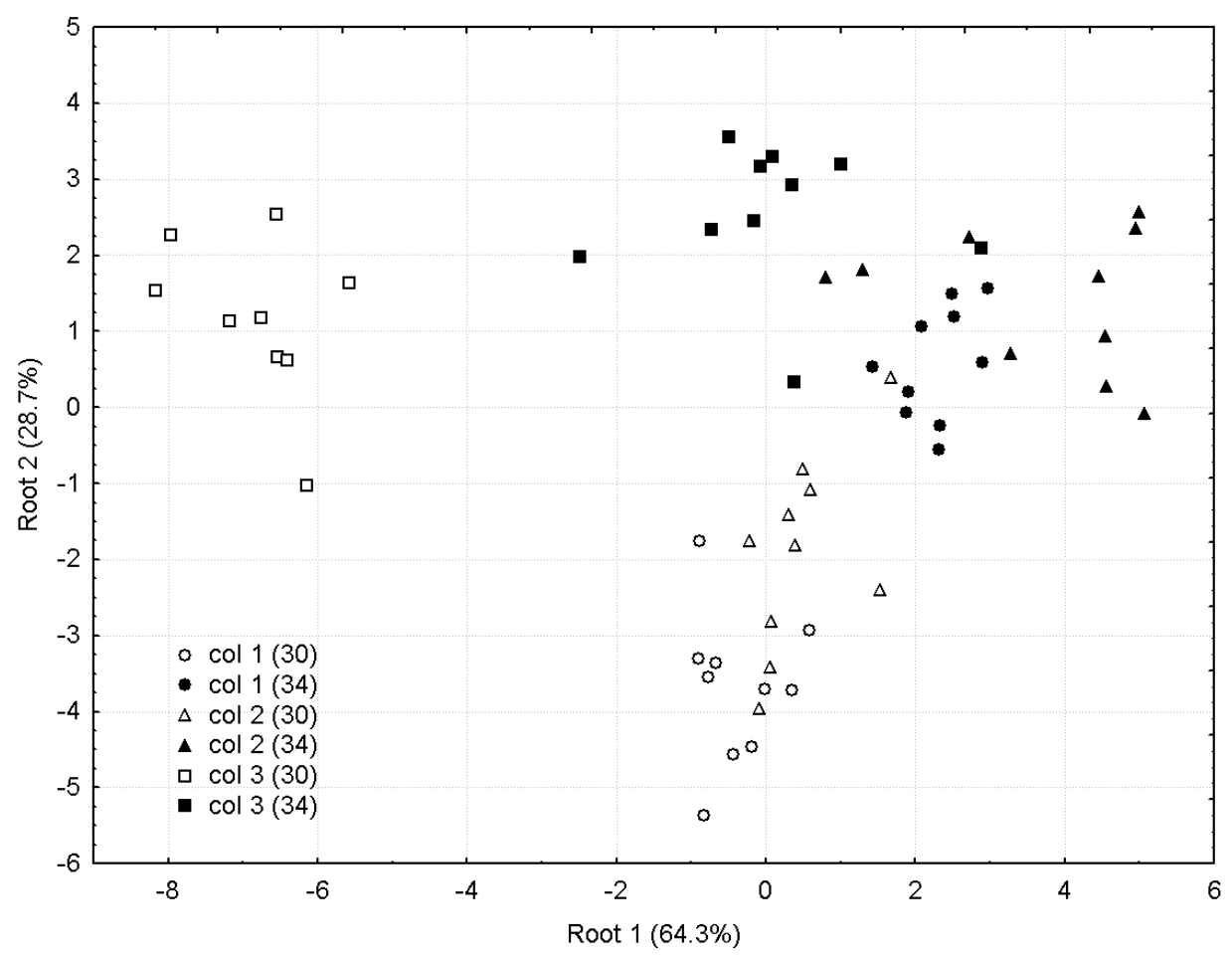

Figure 4. Plot of the first two roots of the discriminant analysis based on the surface hydrocarbons from the three colonies of bees with temperature treatments $34^{\circ} \mathrm{C}$ and $30^{\circ} \mathrm{C}(\mathrm{n}=10$ per treatment per colony $)$. The hydrocarbon profiles of bees from the two temperature treatments show a significant separation both when the colony of origin is included in the analysis (Wilks' Lambda: $0.0049, F_{[45,204]}=10.377, P<0.0001$ ) and when the analysis is based only on two groups, i.e. $34{ }^{\circ} \mathrm{C}$ and $30{ }^{\circ} \mathrm{C}$ reared bees (Wilks' Lambda: 0.1669 , $\left.F_{[9,49]}=27.171, P<0001\right)$.

zero at 4 to 5 days old. Data from previous experiments (McMullan and Brown, 2005) suggest that the susceptibility curve for bees pupated at lower temperatures, whilst declining to near zero at 4 to 5 days old, was above the curve for bees pupated at normal temperatures. Thus, increased susceptibility was due to higher initial susceptibility, rather than an extension of the susceptibility period. Second, Tautz et al. (2003) showed that bees pupated at a low temperature are less active and have a significantly reduced dance and cognitive ability. They also suggested, "that the temperature at which pupae are raised will influence their behavioural performance as adults and may determine the tasks they carry out best inside and outside the hive". Furthermore, Jones et al. (2005) demonstrated that reduced pupation temperature affected the short term learn- ing and memory of the bee. This may result in relatively reduced mobility in these bees. Finally, Pettis et al. (1992) demonstrated that reduced bee mobility coincides with increased mite migration, which occurs almost exclusively at night-time when the bees are in a quiescent mode. Together these studies indicate that changes in bee physiology, in the form of reduced mobility and cognitive ability, are likely to be the mechanism whereby reduced pupation temperature causes increased bee susceptibility.

\subsection{Role of gustatory senses during migration}

Our work also gives insight into the nature of mite migration. In our experiments, 
the mites did not respond to bees that were dead even when they were in close proximity to them. It was only when they came in contact with the bees that there was any response. We do acknowledge that the test protocol essentially registers the mite's initial choice. However, the modified arrangement did allow for the mite to be in contact with the pleural hair of both host bees and hence there was a comparative element in the mite's choice. Thus there is evidence that the mites are not stimulated through their olfactory senses but through their gustatory senses requiring direct contact between the mite and the potential host bee (Tabs. I and II). Hirschfelder and Sachs (1952) have shown that mites responded to contact and not the scent of old or young bees while Sammataro and Needham (1996) have demonstrated that mites detect the different thoracic conditions only if placed on the host. Thus while the findings in our experiments are consistent with the work of Hirschfelder and Sachs (1952), and Sammataro and Needham (1996), it is not clear whether the findings of Phelan et al. (1991) and vanEngelsdorp and Otis (2001) demonstrate a response based on an olfactory or a gustatory sensory reaction. The mites in both cases were put at the centre between two treated areas (and some distance from each) and their locations noted after a 5-minute period. This would indicate that the response of an olfactory sense was being tested. However, Phelan et al. (1991) stated that, "Preliminary observations of female mites walking in the vicinity of honey bee extract revealed no orientation of the mites towards treated areas; however, when placed in contact with a zone treated with young-bee extract, the locomotory tracts of the mite were dramatically different from those of mites placed in hexane treated zones". This would indicate that only a gustatory response was present and raises the questions as to why Phelan et al. (1991) used the particular test methodology.

\subsection{An alternative migration strategy}

Phelan et al. (1991) examined the possible mechanism that determines the increased susceptibility of young bees. It is widely accepted that mites only migrate to young bees and that the susceptibility of young bees approaches zero when they are 4 to 5 days old. This precise time period beyond which susceptibility is effectively zero is not determined by increases in the grooming ability of the bees; bees with little or no grooming ability have also a susceptibility that approaches zero when bees are 4 to 5 days old. Similarly, it is unlikely to be determined by changes in the physiology of the bees. We know that most mites migrate at night when the bees are in a sedentary mode, yet even highly susceptible bees have few mites migrating after $4 / 5$ days. It would be expected that such precision in the age of the bee would have to be determined by the mite, rather than by a defensive mechanism of the bee.

The results from these experiments also raises the question of how the rapid reduction in bee infestation with age (Morgenthaler, 1930; Bailey, 1958; Lee, 1963; Giordani, 1977; Gary et al., 1989) arises in practice. It is postulated that there are potentially two possible (rather than one) modes of mite migration. The first is the generally accepted approach whereby the mite would transfer to a neighbouring moving bee, test for 'suitability' and either accept or continue to quest for a suitable bee (Sammataro and Needham, 1996). On the assumption that contact between the bees in the hive happens at random, it would be expected that a similar number of young bees of a particular age in the range 0 to 20 days, make contact with a host bee at the time that a foundress female mite is questing. Hence the mites may be seeking a particular chemical cue that identifies a very young bee and must be leaving, for example, almost all of the 5-20 day bees that they visit and must also be moving towards the $<1$-day old bees even in the $<5$-day old bees encountered. This would appear to represent a high-risk strategy for such a small animal that is in danger of desiccation or being groomed off by the bees. This indicates that the mite normally makes several bee migrations before it can accomplish its task and the success rate is likely to be low. External feeding by the mites on unsuitable hosts as observed in the experiments may 
therefore be routinely practiced as an interim measure to reduce the risk of desiccation but the risk of being groomed off during transfer is ever present. Given these costs, a less risky approach may have evolved whereby the migrating mite would 'evaluate' the young bee before transferring. This alternative mode is less risky and given the rapid increase in mite infestation that can take place in a colony (and hence high transfer success rate) and the findings of Pettis et al. (1992) that $85 \%$ of mite transfers take place at night, this is likely to be the selected mode of transfer. Pettis et al. (1992) considered that mites might detect movement of the bees and wait until the host is motionless before initiating dispersal. This would also align with a strategy of reducing risk during mite migration.

\section{ACKNOWLEDGEMENTS}

The authors would like to thank the editor and two anonymous reviewers for their helpful comments. Thanks to the members of Fingal North Dublin Beekeepers' Association and John \& Dorothy Stapleton for access to honey bee colonies. Thanks also to Richard Jones, International Bee Research Association, for providing copies of old beekeeping papers.

Rôle possible de signaux chimiques chez Apis mellifera mellifera dans le comportement de recherche de l'hôte de l'acarien Acarapis woodi.

Apis mellifera / Acarapis woodi / acarien / migration / nymphose / température de développement

\footnotetext{
Zusammenfassung - Chemische Reize beim Wirtsfindeverhalten der Tracheenmilbe (Acarapis woodi) gegenüber Honigbienen (Apis mellifera mellifera). Seit über 100 Jahren wird die Tracheenmilbe Acarapis woodi mit dem Zusammenbruch von Bienenvölkern in Verbindung gebracht. Es ist bekannt, dass die Milben von älteren Bienen zu jüngeren Wirtsstadien (meist weniger als 4 Tage alt) wechseln und dass die Anfälligkeit eines Bienenvolkes gegenüber einem Befall mit Tracheenmilben vor allem vom Putztrieb der Bienen abhängt. In einem kürzlich durchgeführten Experiment konnte gezeigt werden, dass die Anfälligkeit von Bienen, die sich bei einer niedrigeren Temperatur $\left(30^{\circ} \mathrm{C}\right)$ verpuppten, signifikant erhöht war. Diese erhöhte Anfälligkeit konnte dabei nicht durch
}

einen geringeren Putztrieb erklärt werden. In der vorliegenden Arbeit untersuchten wir, ob diese erhöhte Anfälligkeit möglicherweise durch den Einfluss chemischer Reize auf das Wanderungsverhalten der Milben verursacht wird (Abb. 3). Bienen, die sich bei $30{ }^{\circ} \mathrm{C}$ bzw. bei normaler Brutnesttemperatur von $34{ }^{\circ} \mathrm{C}$ verpuppt hatten, unterschieden sich signifikant im Muster ihrer kutikulären Kohlenwasserstoffe. Verhaltensexperimente mit einem Wahl-Biotest zeigten allerdings, dass chemische Reize nicht die Präferenz der Milben für Bienen, die sich bei $30{ }^{\circ} \mathrm{C}$ verpuppt hatten, erklären können (Tab. III). Wir schließen daraus, dass andere Faktoren wie zum Beispiel eine durch niedrige Verpuppungstemperaturen verursachte verringerte Mobilität oder Wahrnehmungsfähigkeit der Bienen für die erhöhte Anfälligkeit verantwortlich sind. Unsere Untersuchung zeigt auch, dass die Milben eher durch Geschmack als durch Geruchsreize in ihrem Verhalten beeinflusst werden. Es wird ein neues Modell für die Milbenwanderung zu den jungen Bienen $(<4$ Tage) vorgestellt, bei dem der Wirtswechsel und damit die Verbreitung des Parasiten mit einem geringeren Risiko für die Muttermilben verbunden sind.

Apis mellifera / Acarapis woodi / Tracheenmilbe / Milbenwanderung / Verpuppungstemperatur

\section{REFERENCES}

Adam B. (1987) The honey-bee tracheal mite - fact and fiction, Am. Bee J. 127, 36-38.

Aitchison J. (1986) The statistical analysis of compositional data: monographs in statistics and applied probability, Chapman and Hall.

Bailey L. (1958) The epidemiology of the infestation of the honeybee, Apis mellifera L. by the mite Acarapis woodi Rennie and the mortality of infested bees, Parasitology 48, 493-506.

Bailey L. (1961) The natural incidence of Acarapis woodi (Rennie) and the winter mortality of honeybee colonies, Bee World 42, 96-100.

Danka R.G., Villa J.D. (1998) Evidence of autogrooming as a mechanism of honeybee resistance to tracheal mite infestation, J. Apic. Res. 37, 39-46.

Danka R.G., Villa J.D. (2005) An association in honey bees between autogrooming and the presence of migrating tracheal mites, Apidologie 36, 331-333.

Eischen F.A., Cardoso-Tamez D., Wilson W.T., Dietz A. (1989) Honey production of honey bee colonies infested with Acarapis woodi (Rennie), Apidologie 20, 1-8.

Francis B.R., Blanton W.E., Littlefield J.L., Nunamaker R.A. (1989) Hydrocarbons of the cuticle and hemolymph of the adult honey bee 
(Hymenoptera: Apidae), Ann. Entom. Soc. Am. 82, 486-494.

Gary N.E., Page R.E. (1987) Phenotypic variation in susceptibility of honey bees, Apis mellifera, to infestation to tracheal mites, Acarapis woodi, Exp. Appl. Acarol. 3, 291-305.

Gary N.E., Page R.E. Jr., Lorenzen K. (1989) Effect of age of worker honey bees (Apis mellifera) on tracheal mite (Acarapis woodi) infestation, Exp. Appl. Acarol. 7, 153-160.

Giordani G. (1967) Laboratory research on Acarapis woodi Rennie, the causative agent of acarine disease of the honeybee, Note 5, J. Apic. Res. 6, $147-157$.

Giordani G. (1977) Facts about acarine mites, Proceedings of the 26th International Apicultural Congress, Adelaide, Australia, pp. 459-467.

Hirschfelder H., Sachs H. (1952) Recent research on acarine disease, Bee World 33, 201-209.

Jones J.C., Helliwell P., Beekman M., Maleszka R., Oldroyd B.P. (2005) The effects of rearing temperature on developmental stability and learning and memory in the honey bee, Apis mellifera, J. Comp. Physiol. 191, 1121-1129.

Lee D.C. (1963) The susceptibility of honey bees of different ages to infestation by Acarapis woodi (Rennie), J. Inst. Pathol. 5, 11-15.

McMullan J.B., Brown M.J.F. (2005) Brood pupation temperature affects the susceptibility of honeybees (Apis mellifera) to infestation by tracheal mites (Acarapis woodi), Apidologie 36, 97-105.

McMullan J.B., Brown M.J.F. (2006) The role of autogrooming in the differential susceptibility to tracheal mite (Acarapis woodi) infestation of honeybees (Apis mellifera) held at both normal and reduced temperatures duration pupation, Apidologie 37, 471-479.
McMullan J.B., Brown M.J.F. (2009) A qualitative model of mortality in honey bee (Apis mellifera) colonies infested with tracheal mites (Acarapis woodi), Exp. Appl. Acarol. 47, 225-234.

Morgenthaler O. (1930) New investigations on acarine disease, Bee World 11, 49-51.

Morgenthaler O. (1931) An acarine disease experimental apiary in the Bernese lake district and some of the results obtained there, Bee World 12, 8-10.

Otis G.W., Scott-Dupree C.D. (1992) Effects of Acarapis woodi on overwintered colonies of honey bees (Hymenoptera: Apidae) in New York, J. Econ. Entomol. 85, 40-46.

Pettis J.S., Wilson W.T., Eischen F.A. (1992) Nocturnal dispersal by female Acarapis woodi in honey bee (Apis mellifera) colonies, Exp. Appl. Acarol. 15, 99-108.

Phelan L.P., Smith A.W., Needham G.R. (1991) Mediation of host selection by cuticular hydrocarbons in the honeybee tracheal mite Acarapis woodi (Rennie), J. Chem. Ecol. 17, 463-473.

Sammataro D., Needham G.R. (1996) Host-seeking behaviour of tracheal mites (Acari: Tarsonemidae) on honey bees (Hymenoptera: Apidae), Exp. Appl. Acarol. 20, 121-136.

Tautz J., Maier S., Groh C., Rossler W., Brockmann A. (2003) Behavioral performance in adult honey bees is influenced by the temperature experienced during their pupal development, Proc. Natl. Acad. Sci. USA 100, 7343-7347.

vanEngelsdorp D., Otis G.W. (2001) The role of cuticular compounds in the resistance of honey bees (Apis mellifera) to tracheal mites (Acarapis woodi), Exp. Appl. Acarol. 25, 593-603.

Waladde S.M., Rice J.J. (1982) The sensory basis of tick feeding behaviour, Physiology of ticks, in: Obenchain F.D., Galun R. (Eds.), Pergamon Press, New York, NY, pp. 71-118. 